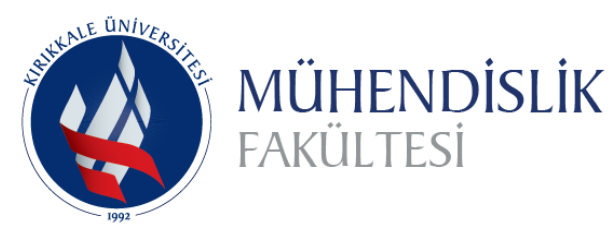

\author{
Uluslararası Mühendislik \\ Araştırma ve Geliştirme Dergisi UMAGD, (2022) 14(1), 256-261. \\ International Journal of \\ Engineering Research and \\ Development \\ 10.29137/umagd.1038327
}

Cilt/Volume:14 Sayı/Issue:1 Ocak/January 2022

Araştırma Makalesi / Research Article

\title{
Farklı Kalıp ve Firın Sıcaklıkları Kullanılarak Yarı Katı Kalıplama Yöntemi ile Şekillendirilen A356 Alaşımının Sertlik ve Mikroyapı Özelliklerinin İncelenmesi
}

\section{The Investigation of Hardness and Microstructural Properties of A356 Alloy Shaped by Semi-Solid Molding Method Using Different Mold and Furnace Temperatures}

\author{
Doğan Şimşek $^{1 *}$ iD , İjlal Şimşek ${ }^{1 *}$ (iD), Dursun Özyürek ${ }^{2 *}$ iD \\ ${ }^{1}$ Milli Savunma Üniversitesi, Kara Astsubay Meslek Yüksekokulus, 10100, Balıkesir, TÜRKIYYE \\ ${ }^{2}$ Karabük Üniversitesi, Teknoloji Fakultesi, 78050, Karabük, TÜRKIYYE
}

Başvuru/Received: 18/12/2021Ｋabul/Accepted: 31/12/2021Ｃ̧evrimiçi Basım/Published Online: 31/01/2022

Son Versiyon/Final Version: 31/01/2022

\begin{abstract}
$\ddot{O} \mathbf{z}$
Bu çalıșmada, yarı katı kalıplama yöntemi ile farklı fırın ve kalıp sıcaklıklarında üretilen A356 alaşımının mikroyapı, sertlik ve tane boyutu dağılımı incelenmiştir. A356 alaşımı tozlar, titreşimli değirmende 15 dakika karıştırılmış ve ardından $800 \mathrm{MPa}$ basınç altında ve $\varnothing 12 \times 8 \mathrm{~mm}$ boyutlarında ham numuneler üretilmiştir. Ham numunelerin yarı katı işlemlerinde iki farklı firın $\left(590{ }^{\circ} \mathrm{C}\right.$ ve $\left.600{ }^{\circ} \mathrm{C}\right)$ ve kalıp sıcaklıkları $\left(350^{\circ} \mathrm{C}\right.$ ve $\left.550^{\circ} \mathrm{C}\right)$ kullanılmıştır. Ham numuneler, belirtilen firın ve kalıp sıcaklıklarında 1 dakika preslendikten sonra hızla oda sıcaklığına soğutulmuştur. Yapılan çalışmalarda firın ve kalıp sıcaklığının yarı katı kalıplama işlemi için önemli parametreler olduğu görülmüștür. Mikroyapı da büyük ölçüde küreselliğin sağlandığı tespit edilmiștir. En yüksek küresellik oranı $590{ }^{\circ} \mathrm{C}$ firın ve $550{ }^{\circ} \mathrm{C}$ kalıp sicaklığında $\% 64$ olarak elde edilmiştir. Tane boyutu dağılım sonuçlarında $590{ }^{\circ} \mathrm{C}$ firın ve $350{ }^{\circ} \mathrm{C}$ kalıp sıcaklığında ince taneli yapı elde edilmiştir. Sertlik sonuçlarında en yüksek sertlik, ince tane yapının elde edildiği kalıp ve fırın sıcaklığında $\left(590^{\circ} \mathrm{C}\right.$ firın, $350^{\circ} \mathrm{C}$ kalıp) elde edilmiştir.
\end{abstract}

\section{Anahtar Kelimeler}

"A356 alaşımı, yarı katı kalıplama, tane boyutu, küresellik oranı"

\begin{abstract}
In this study, were investigated the microstructure, hardness and granulometry of the A356 alloy produced of different furnace and mold temperatures by the semi-solid molding method. A356 alloy powders were mixed in the vibrating mill for 15 minutes, after green compacts were produced under $800 \mathrm{MPa}$ pressure and $\emptyset 12 \times 8 \mathrm{~mm}$ dimensions. In the processes semi-solid of green compacts used two different furnace $\left(590^{\circ} \mathrm{C}\right.$ and $\left.600{ }^{\circ} \mathrm{C}\right)$ and mold temperatures $\left(350{ }^{\circ} \mathrm{C}\right.$ and $\left.550{ }^{\circ} \mathrm{C}\right)$. Green compacts were rapidly cooled to room temperature after 1 minute pressed at specified furnace and mold temperatures. In the studies, were seen that the furnace and mold temperature is important parameters for the process semi-solid molding. In the microstructure were determined that has been achieved sphericity to a large extent. The highest sphericity rate was obtained as $64 \%$ at $590{ }^{\circ} \mathrm{C}$ furnace and $550{ }^{\circ} \mathrm{C}$ mold temperature. In the grain size distribution results, fine-grained structure was obtained at $590{ }^{\circ} \mathrm{C}$ furnace and $350{ }^{\circ} \mathrm{C}$ mold temperature. In the hardness results, the highest hardness was obtained at the mold and furnace temperature $\left(590^{\circ} \mathrm{C}\right.$ furnace, $350^{\circ}$ $\mathrm{C}$ mold) where the fine grain structure was obtained.
\end{abstract}

Key Words

"A356 alloys, semi-solid molding, grain size, sphericity rate" 


\section{Giriş}

A356 alaşımları en yaygın kullanılan Al-Si-Mg alaşımlarıdır. Bu alaşımlar özellikle düşük yoğunluğu, yüksek dökülebilirlik kabiliyeti, korozyon direnci ve kaynaklanabilirliği nedeniyle savunma sanayi, havacılık sanayi ve otomotiv sanayisinde yaygın olarak kullanılmaktadır. Alaşımın kimyasal bileşiminde bulunan silisyum akışkanlığa, korozyon direncine ve mekanik özelliklere önemli ölçüde katkıda bulunmaktadır. Alaşımın içerisinde bulunan magnezyum ise akma, çekme dayanımı ve süneklilik üzerinde etkilidir (Şimşek vd. 2020). Bu alaşımlar yaygın olarak döküm (Tuncay vd. 2013; Dwivedi, 2004; Yıldırım ve Özyürek 2014), toz metalürjisi (Kim vd. 2012; Ozyurek vd. 2015) ve sprey birikimi (Laha vd. 2005) gibi çeşitli yöntemler kullanmaktadır. Bu üretim yöntemlerine ilaveten yarı katı şekillendirme yöntemi diğer üretim yöntemleri ile karşılaştırıldığında çok daha az gözenek, düşük çalışma basınçlarında üretim yapabilme, uzun kalıp ömrü ve düşük şekillendirme sıcaklıkları nedeniyle daha az enerji ihtiyacı gibi bazı avantajlar sağlamaktadır (Zoqui vd. 2004; Atkinson vd Liu 2008; Aztekin vd. 2010). Bu özelliklerin yanı sıra yarı katı şekillendirme yöntemiyle küresel yapılı malzeme üretimi yarı katı şekillendirme yönteminin sağladığı diğer bir avantajdır (Özyürek vd.2012). Geleneksel döküm yöntemi ile üretilen alaşımlarda, oksitlenmeden kaynaklı gözenek olarak tanımlanan döküm kusurları, katılaşma sırasında oluşan çekme hataları gibi kusurlar malzemenin mekanik özelliklerini azaltmaktadır (Otarawanna ve Dahle, 2011). Bunun yanı sıra geleneksel döküm yöntemi ile üretilen Al alaşımlarının sahip olduğu klasik iğneli dentritik yapının alaşımın özelliklerini doğrudan etkilemektedir. Bununla birlikte katılaşma sırasında dentritik kollar arasında oluşan mikro gözenekler malzemenin mekanik özelliklerini olumsuz yönde etkilemektedir.

Yapılan çalışmada, yarı katı şekillendirme işleminde farklı kalıp ve firın sıcaklıkları kullanılarak A356 alaşımı malzeme üretilmiştir. Üretilen A356 alaşımı malzemenin küreselleşme oranı, sertlik ve tane boyutu ile fırın ve kalıp sıcaklıkları arasındaki ilişki incelenmiştir.

\section{Malzeme ve Metod}

Deneysel çalışmalarda, özellikle otmotiv sektöründe yaygın olarak kullanılan A356 (Al-Si-Mg) alaşımı kullanılmışıır. Külçe halinde temin edilen alaşım gaz atomizasyon yöntemiyle toz haline getirilmiştir. Üretilen tozların boyutu yaklaşı $30-50 \mu \mathrm{m}$ aralığındadır. Kullanılan A356 alaşımının kimyasal bileşimi Tablo 1'de verilmiştir

Tablo 1. Deneysel çalışmalarda kullanılan A356 alaşımının kimyasal bileşimi (\% ağ.)

\begin{tabular}{cccccccccc}
\hline \multirow{2}{*}{ A356 } & $\mathbf{S i}$ & $\mathbf{M g}$ & $\mathbf{T i}$ & $\mathbf{F e}$ & $\mathbf{Z n}$ & $\mathbf{M n}$ & $\mathbf{C u}$ & $\mathbf{P b}$ & $\mathbf{A l}$ \\
\cline { 2 - 10 } & 6,5 & 0,4 & 0,2 & 0,15 & 0,05 & 0,03 & 0,03 & 0,03 & Kalan \\
\hline
\end{tabular}

Toz haline getirilen A356 alaşımı tozlar titreşimli tip değirmende $15 \mathrm{dk}$. karıştırılmıştır. Karıştırma işlemi sonrasında hazırlanan tozlar tek yönlü hidrolik preste $800 \mathrm{MPa}$ basınç altında $Ø 12 \times 8 \mathrm{~mm}$ boyutlarında ham numuneler üretilmiştir. Yarı katı kalıplama işleminde PROTHERM marka silindirik boru tipi $1200 \pm 2{ }^{\circ} \mathrm{C}$ kapasiteli firın kullanılmıştır. Yarı katı kalıplama işleminde grafit kalıp kullanılmıştır. Yarı katı işlem firınında iki farklı firın sıcaklığ $1350{ }^{\circ} \mathrm{C}$ ve $\left.550{ }^{\circ} \mathrm{C}\right)$ ve iki farklı kalıp sıcaklığ $1\left(590{ }^{\circ} \mathrm{C}\right.$ ve $\left.600{ }^{\circ} \mathrm{C}\right)$ kullanılmıştır (Özyürek, vd. 2012; Aztekin, vd. 2010). Soğuk şekillendirilen ham numuneler, belirlenen firın ve kalıp sıcaklıklarında $30 \mathrm{dk}$. beklendikten sonra $20 \mathrm{kN}$ pres kuvveti ile $1 \mathrm{dk}$. süre preslenmiş ve ardından oda sıcaklığına hızlı bir şekilde soğutulmuştur. Elde edilen yarı katı şekillendirilmiş numuneler standart metalografi işlemleri uygulanmıştır. Mikroyapı incelemeleri için hazırlanan numuneler $2 \mathrm{ml} \mathrm{HF}, 3 \mathrm{ml} \mathrm{HCI}, 20 \mathrm{ml} \mathrm{HNO} 3,175 \mathrm{ml} \mathrm{H} 2 \mathrm{O}$ (Keller's) solüsyonu kullanılarak 30 saniye süreyle dağlanmıştır. Dağlanan numunelerin mikroyapı incelemelerinde Meiji marka ML7100 optik mikroskop kullanılmıştır. Küresellik oranı ölçümü, MSQ PLUS 6.5 metalografik ölçüm ve analiz programında ASTM E112 standartlarına göre yapılmıştır. Sertlik ölçümleri, AFFRI VRSD251 markalı sertlik cihazında HV2.5 yük olarak 10 saniye süre ile ölçülmüştür. Sertlik ölçümleri her numuneden merkezden diş yüzeye doğru 5 farklı ölçüm noktasından alınmıştır. Tane boyutu ölçümü ve dağılımı ImageJ görüntü analiz programı kullanılarak her görüntüden 50 ölçüm yapılmış ve \% tane boyutu dağılımı olarak belirlenmiş̧ir.

\section{Bulgular ve Tartışma}

Şekil 1'de başlangıç malzemesi olarak kullanılan A356 alaşımının optik mikroskop görüntüsü verilmiştir.

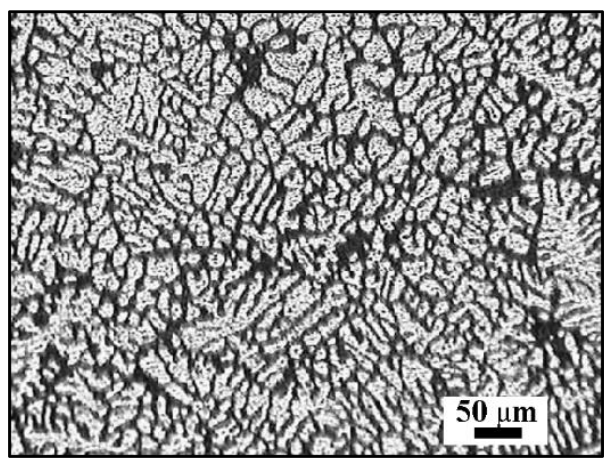


Şekil 1. Başlangıç malzemesi olarak kullanılan A356 alaşımının optik mikroskop görüntüsü

Şekil 1'de verilen başlangıç malzemesi olarak kullanılan Al-Si (A356) alaşımının mikro yapısı incelendiğinde, klasik döküm yöntemi ile elde edilen Al-Si alaşımlarının standart dentritik yapıya sahip olduğu görülmektedir. Malzemelerde dentritik yapı mekanik özellikleri ilgilendiren önemli bir parametredir (Şimşek vd. 2020) Dentritik yapıya sahip alaşımlarda dentritik kollar arasındaki boşluklar ve mesafeler alaşımın mekanik özelliklerini doğrudan ilgilendirmektedir. Farklı fırın ve kalıp sıcaklıklarında üretilen A356 alaşımlarının optik mikroskop görüntüleri Şekil 2'de verilmiştir.

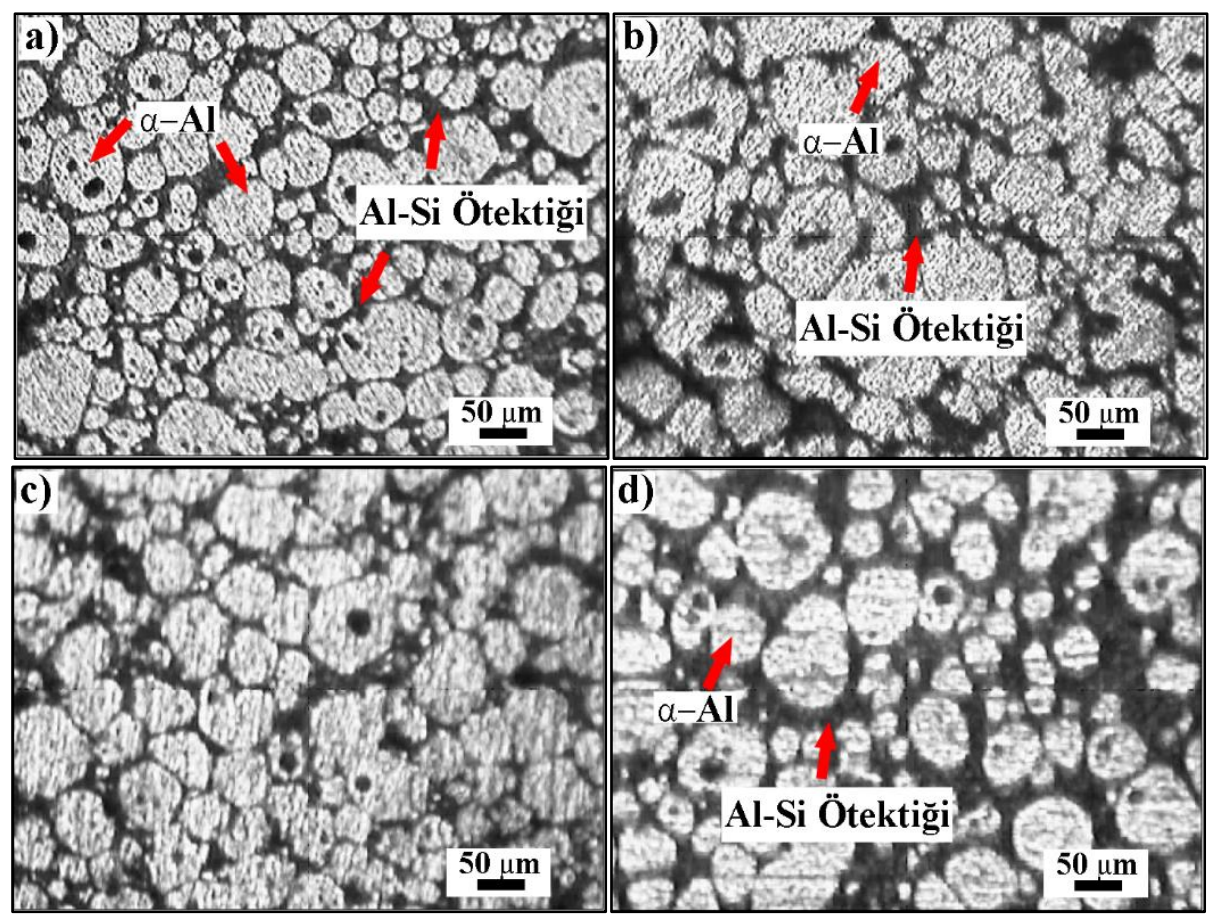

Şekil 2. Farklı fırın ve kalıp sıcaklıklarında üretilen A356 alaşımlarının optik mikroskop görüntüleri a)590F/350K b) 590F/550K c) $600 \mathrm{~F} / 350 \mathrm{~K}$ d) $600 \mathrm{~F} / 550 \mathrm{~K}$

Şekil 2'de verilen farklı kalıp ve firın sıcaklılarında üretilen A356 alaşımlarının optik mikroskop görüntüleri incelendiğinde, bütün sıcaklıklarda başlangıçta dentritik yapının tamamen küresel forma dönüştüğü görülmektedir. En ince taneli yapının $590{ }^{\circ} \mathrm{C}$ firın 350 ${ }^{\circ} \mathrm{C}$ kalıp sıcaklığında üretilen alaşımda olduğu görülmektedir. Sıcaklığın küreselleşme oranında etkili bir parametre olduğu anlaşılmaktadır. Kalıp sıcaklığının artmasıyla küreselleşme oranının yanı sıra tane büyüme eğiliminin de arttığı görülmektedir. Ayrıca fırın sıcaklığının artmasıyla Al-Si ötektik bölgelerin (siyah bölgeler) arttığı görülmektedir (Özyürek, 2011). Farklı firın ve kalıp sıcaklıklarında yarı katı kalıplama yöntemi ile üretilen A356 alaşımlarının tane boyut dağılımı Şekil 3’te verilmiştir.

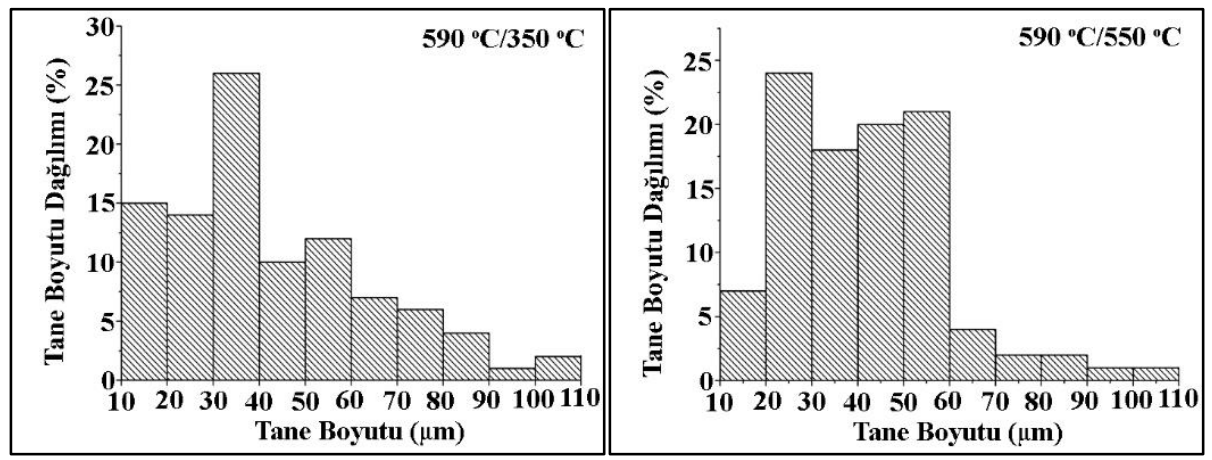




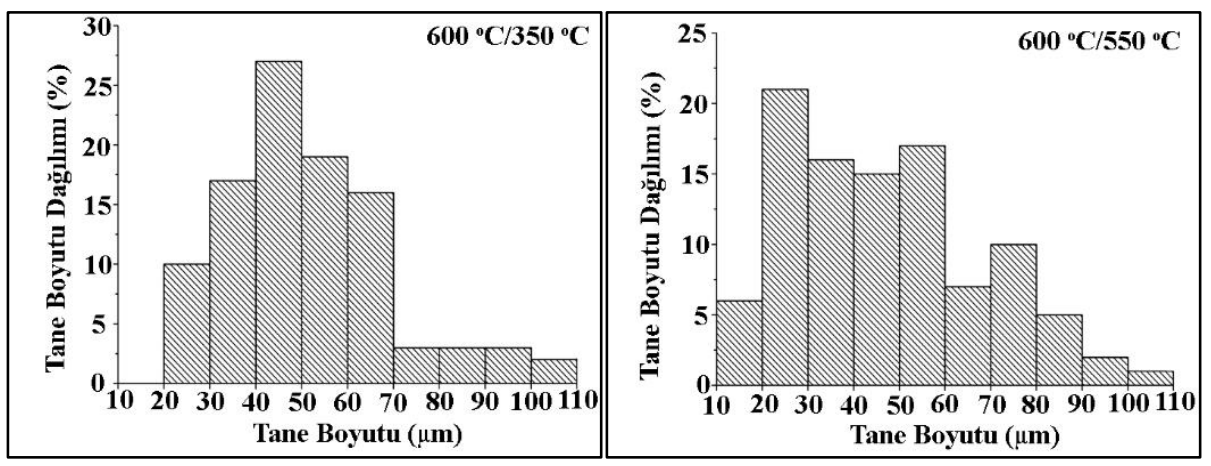

Şekil 3. Farklı firın ve kalıp sıcaklıklarında yarı katı kalıplama yöntemi ile üretilen A356 alaşımların tane boyut dağılımı

Şekil 3' de verilen farklı firın ve kalıp sıcaklıklarında yarı katı kalıplama yöntemi ile üretilen A356 alaşımların tane boyutu dağılımları incelendiğinde, ince taneli yapının $590{ }^{\circ} \mathrm{C}$ firın ve $350{ }^{\circ} \mathrm{C}$ sıcaklığında elde edildiği görülmektedir. $590{ }^{\circ} \mathrm{C}$ firın, $350{ }^{\circ} \mathrm{C}$ kalıp sıcaklığında tane boyut dağılımın yüksek oranda $10-40 \mu \mathrm{m}$ aralığında yaklaşık \%15'ten büyük bir dağılım olduğu görülmektedir. Kalıp sıcaklığının $550{ }^{\circ} \mathrm{C}$ olmasıyla tane boyut dağılımının 10-20 $\mu \mathrm{m}$ aralığında tane boyutu dağılımın azaldığı görülürken 20-60 $\mu \mathrm{m}$ aralığında tane boyutu dağılımında ciddi bir artış olduğu görülmektedir. Benzer şekilde firın sıcaklığının $600{ }^{\circ} \mathrm{C}^{\prime}$ ye çıkmasıyla iki kalıp sıcaklığında tane boyutlarında artış olduğu görülmektedir. $600{ }^{\circ} \mathrm{C}$ firın $350{ }^{\circ} \mathrm{C}$ kalıp sıcaklığında kalıplanan alaşımın yapısında tane boyutu dağılımının $20-60 \mu \mathrm{m}$ aralığında yoğunlaştığı görülürken, kalıp sıcaklığının $550{ }^{\circ} \mathrm{C}$ olmasıyla tane boyutu dağılımının 20-60 $\mu \mathrm{m}$ aralığında azalma görülürken 70-100 $\mu \mathrm{m}$ aralığında boyutları dağılımında artışın olduğu görülmektedir. Sıcaklığın artmasıyla (hem fırın hem de kalıp) tane boyutlarında artış, alaşımın işlem sırasındaki katı sıvı oranı ile ilişkilidir (Özyürek vd, 2008). Farklı firın ve kalıp sıcaklıklarında yarı katı kalıplama yöntemi ile üretilen A356 alaşımlarının küresellik oranı sonuçları Şekil 4'te verilmiştir.

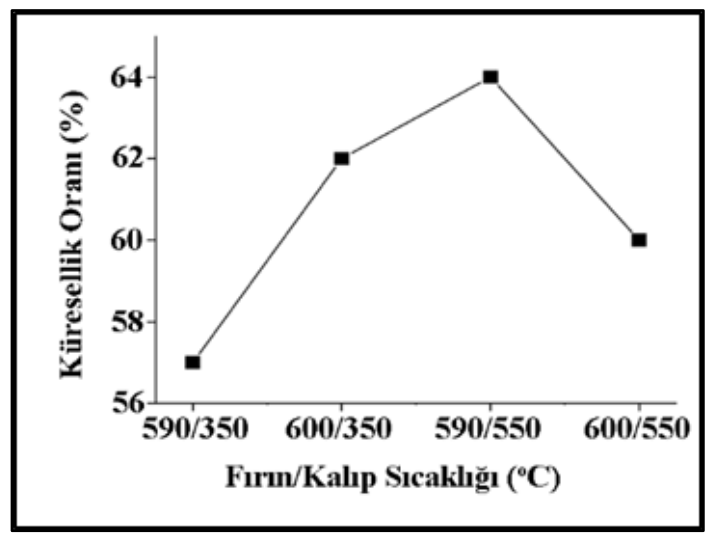

Şekil 4. Farklı fırın ve kalıp sıcaklıklarında yarı katı kalıplama yöntemi ile üretilen A356 alaşımlarının küresellik oranı

Şekil 4.'te verilen farklı firın ve kalıp sıcaklarında yarı katı kalıplama yöntemiyle üretilen A356 alaşımlarının küresellik oranları incelendiğinde, düşük fırın ve yüksek kalıp sıcaklığında küresellik oranının arttığı görülmektedir. Küresellik oranındaki bu artış sıvı haldeki Al-Si ötektik fazının viskozitesi ile açıklanabilir. Kalıp sıcaklığıyla birlikte firın sıcaklığının artması viskozitenin azalması azalmasına neden olur. Azalan viskozite $\alpha$-Al tanelerinin küreselleşmesini engeller. Şimşek vd. tarafından yapılan bir çalışmada benzer sonuçların elde edildiği rapor edilmiştir (Şimşek vd. 2020). En yükssek küresellik oranı $590^{\circ} \mathrm{C}$ firın $550{ }^{\circ} \mathrm{C}$ kalıp sıcaklığında yaklaşık olarak \%64 olarak elde edildiği görülmektedir. Fırın sıcaklığının artmasıyla aynı kalıp sıcaklıklarında küresellik oranı artmaktadır. Benzer şekilde aynı fırın sıcaklıklarında kalıp sıcaklığının artması küresellik oranını artırmaktadır. Ancak yüksek firın ve kalıp sıcaklıklarında küresellik oranında azalma olduğu görülmektedir. Yarı katı kalıplama yöntemi ile şekillendirmede sıcaklık önemli bir parametredir. Düşük fırın sıcaklıklarında alaşımın katı-sıvı faz oranında katı fazın fazla olması $\alpha$-Al tanelerinin küreselleşmesini engellemektedir. Bununla birlikte artan kalıp sıcaklığı ile katı-sıvı faz oranındaki sıvı faz miktarının artması $\alpha$-Al tanelerinin küreselleşme eğilimini artırmaktadır. Fırın sıcaklığı ile kalıp sıcaklıklarının da yükselmesi sıvı faz miktarının daha fazla artırır. Sıvı faz miktarının artması ise küresellik oranının azalmasına ve tanelerin büyümesine neden olmaktadır (Özyürek vd. 2008; Tzimas, ve Zavaliangos, 2000). Farklı fırın ve kalıp sıcaklıklarında yarı katı kalıplama yöntemiyle şekillendirilen A356 alaşımlarının sertlik sonuçları Şekil 5'te verilmiştir. 


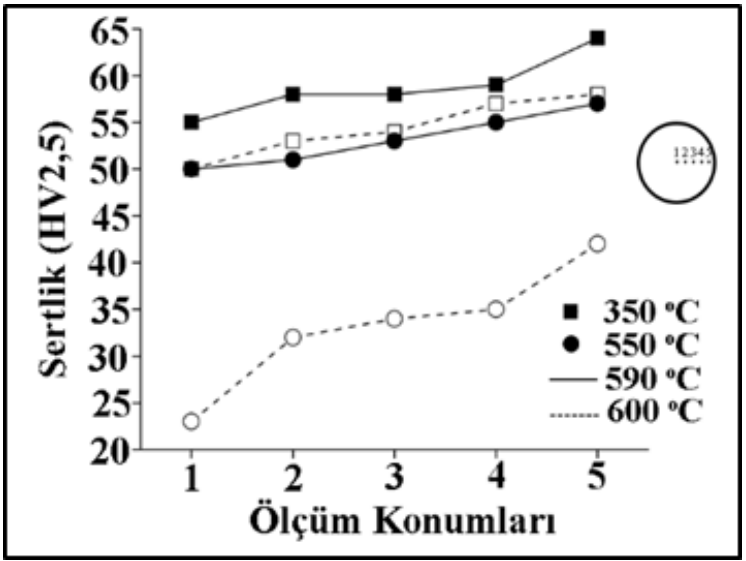

Şekil 5. Farklı fırın ve kalıp sıcaklıklarında yarı katı kalıplama yöntemi ile üretilen A356 alaşımların sertlik sonuçları (Maksimum Hata Oran $1 \pm 8,7)$

Şekil 5'te verilen farklı fırın ve kalıp sıcaklıklarında yarı katı kalıplama yöntemiyle şekillendirilen A356 alaşımlarının sertlik sonuçları incelendiğinde, en yüksek sertlik $590{ }^{\circ} \mathrm{C}$ firın $350{ }^{\circ} \mathrm{C}$ kalıp sıcaklığında yarı katı şekillendirilen A356 alaşımında elde edilmiştir. Yarı katı kalıplama yöntemiyle şekillendirme işleminde kalıp sıcaklı̆ğını sertlik üzerinde etkili bir parametre olduğu görülmektedir. İnce taneli yapının elde edildiği kalıp ve firın sıcaklığında maksimum sertlik elde edilmiştir. Elde edilen sonuçlar Şekil 3'te verilen tane boyutu dağılımı sonuçları ile birbirini desteklemektedir. Üretilen alaşımın sertliğinde elde edilen artış tane sınırı mukavemet artırma mekanizması ile açıklanabilir. İnce taneli yapı ile alaşımın birim alandaki tane sınırlarının artması dislokasyonu hareketlerinin engellenmesi ile alaşımın sertliğinde artışa neden olur. Merkezden dış yüzeye yapılan ölçümlerde bütün sıcaklıklarda sertliğin arttığı görülmektedir. Yarı katı kalıplama yöntemi ile şekillendirilen malzemelerin soğumasıyla dış yüzeyin merkez ile karşılaştırıldığında daha serttir (Aztekin vd. 2010; Idegomori, 1998).

\section{Sonuçlar}

Yarı katı kalıplama yöntemi ile şekillendirilen A356 alaşımlarında farklı fırın ve kalıp sıcaklıklarının alaşımın başlangıçtaki dentritik yapının, bütün çalışma sıcaklıklarında büyük oranda küresel forma dönüştügü̈ görülmüştür. Yarı katı kalıplama yöntemiyle üretim sürecinde kalıp ve firın sıcaklıklarının önemli birer parametre olduğu görülmüştür.

Tane boyutu dağılımı sonuçlarında en ince taneli yapının $590{ }^{\circ} \mathrm{C}$ firın ve $350{ }^{\circ} \mathrm{C}$ kalıp sıcaklıklarında elde edilmiştir. Çalışma sıcaklıklarının artmasıyla tane boyutunun da artma eğiliminde olduğu görülmüştür. En yüksek tane boyutu dağılımı $600{ }^{\circ} \mathrm{C}$ firın 550 ${ }^{\circ} \mathrm{C}$ kalıp sicaklıklarında elde edilmiştir.

Üretilen alaşımın yapısında dentritik yapının küreselleşmesinde kalıp sıcaklığının daha etkili olduğu görülmüştür. Kalıp sıcaklığının artmasıyla küreselleşme oranında artma elde edilmiştir. En düşük küresellik oranının $590{ }^{\circ} \mathrm{C}$ firın, $350{ }^{\circ} \mathrm{C}$ kalıp sıcaklığında $\% 57$ oranında elde edilirken en yüksek küresellik oran $1590^{\circ} \mathrm{C}$ firın, $550^{\circ} \mathrm{C}$ kalıp sıcaklığında $\% 63$ olarak elde edilmiştir.

Üretilen alaşımın sertliğinde kalıp ve firın sıcaklığının artmasıyla azalma olduğu görülmüştür. En yüksek sertlik, $590{ }^{\circ} \mathrm{C}$ firın $350{ }^{\circ} \mathrm{C}$ kalıp sıcaklığında elde edilirken, en düşük sertlik $600^{\circ} \mathrm{C}$ firın, $550^{\circ} \mathrm{C}$ kalıp sıcaklığında elde edilmiştir.

Sertlik ölçümlerinde merkezden dış yüzeye doğru gidildikçe bütün çalışma sıcaklıklarında Setlik değerlerinde artış elde edilmiştir.

\section{Referanslar}

D. K. Dwivedi, (2004), Sliding temperature and wear behaviour of cast Al-Si-Mg alloys, Material Science and Engineering A, 382 (12), 328-334.

D. Özyürek, (2011), The effect of semi-solid processing parameters on microstructure in Al-7wt.Si alloy Scientific Research and Essays, 6(29), 6222-6226.

D. Özyürek, M. Yıldırım, İ. Çiftçi, (2012), The tribological properties of A356-SiCp metal-matrix composites fabricated by thixomoulding technique, Science and Engineering of Composite Materials, 19(4), 351-356.

D. Ozyurek, T. Tunçay, H. Evlen, İ. Ciftci, (2015), Synthesis, characterization and dry sliding wear behavior of in-situ formed TiAl3 precipitate reinforced A356 alloy produced by mechanical alloying method, Material Research, 18(4), 813-820.

E. J. Zoqui, M. Paes, M. H. Robert, (2004), Effect of macrostructure and microstructure on the viscosity of the A356 alloy in the semisolid state, Journal of Materials Processing Technology, 153, 300-306.

H. Aztekin, D. Ōzyūrek, K. Çetinkaya, (2010), Production of hypoeutectic Al-Si alloy-based metal matrix composite with thixomoulding processing, High Temperature Materials and Processes, 29(3), 169-178. 
H. J. Kim, J. M. Lee, Y. H. Cho, S. Y. Sung, B. S. Han, Y. S. Ahn, (2012), Microstructures and wear properties of Al-Mg-Si alloy with the addition of ball-milled CoNi powders, Material and Characterization, 70, 137-144.

H. V. Atkinson, D. Liu, (2008), Microstructural coarsening of semisolid aluminium alloys, Materials Science and Engineering: A, 496(1-2), 439-446.

Idegomori, T. (1998). The manufacturing of automobile parts using semi-solid metal processing. In Proc. 5th International Conference on Semi-Solid Processing of Alloys and Composites Colorado, USA, June 23-25.

M. Yildirim, D. Ozyurek, (2014), The effects of mould materials on microstructure and mechanical properties of cast a356 alloy," Journal of Advanced Material and Processes, 2(3-12).

Otarawanna S., Dahle A.K., (2011), Casting of aluminium alloys", Woodhead Publishing Series in Metals and Surface Engineering, $141-154$

Özyürek, D., Aktar, N., Aztekin, H. (2008), Design and construction of a thixo forming unit and production of Al-Si alloys. Materials \& Design, 29(5), 1070-1074.

Şimşek İ., Şimşek D. Özyürek D., (2020), Yarı katı kalıplama yöntemi ile üretilen farklı miktarlarda SiC takviyeli A356 matrisli kompozit malzemelerin aşınma performansının incelenmesi, Politeknik Dergisi, 23(4), 1237-1243.

Şimşek, İ., Şimşek, D., Özyürek, D. (2020), Investigation of the Effect of Ni Amount on the Wear Performance of A356 Cast Aluminum Alloys. Metallurgist, 63(9-10), 993-1001

T. Laha, A. Agarwal, T. McKechnie, K. Rea, S. Seal, (2005), Synthesis of bulk nanostructured aluminum alloy component through vacuum plasma spray technique, Acta Material, 53(20), 5429-5438.

T. Tuncay, S. Tekeli, D. Ozyurek, (2013), Difüzörlü ve difüzörsüz yolluk sistemlerinin A356 alaşımının mekanik özelliklerine etkisi, Gazi University Journal of Engineering and Architecture, 28(2), 241-249.

Tzimas, E., Zavaliangos, A. (2000). Evaluation of volume fraction of solid in alloys formed by semisolid processing. Journal of Materials Science, 35(21), 5319-5330. 